\title{
Preparation of Superhydrophobic ZnO Surface Derived from Wood Template
}

\author{
Xu FENG ${ }^{1, a}$, Jin-Jin LI ${ }^{1, b}$, Tian-Chi WANG ${ }^{1, c,}$, , Kai CHEN ${ }^{1, d}$, Gui-Ju LIU ${ }^{1, e}$, \\ Ching-Ping WONG ${ }^{2, \mathrm{f}, *}$
}

${ }^{1}$ School of Materials Science and Engineering, Nanjing University of Science and Technology, 200 Xiaolingwei Street, Nanjing 210094, China

${ }^{2}$ School of Materials Science and Engineering, Georgia Institute of Technology, Atlanta, GA 30332, USA

a842421798@qq.com, blijinjin_1127@163.com, ctianchiwang@aliyun.com, d646567114@qq.com, '767702833@qq.com, ${ }^{\mathrm{T}} \mathrm{cp} . w o n g @ m s e . g a t e c h . e d u$

${ }^{*}$ Corresponding author

Keywords: Surface, Zinc Oxide, Porous Materials, Wetting.

\begin{abstract}
A superhydrophobic $\mathrm{ZnO} / \mathrm{C}$ surface with a carbon morphology derived from a wood template was fabricated through a solution immersion process, sintering, and modification by FAS. The distribution of zinc oxide on the carbon substrate surface was controlled by changing the mass fraction of $\mathrm{Zn}\left(\mathrm{NO}_{3}\right)_{2}$. After being modified with FAS, the as-prepared $\mathrm{ZnO} / \mathrm{C}$ surface showed analogous superhydrophobic properties, with a water contact angle of approximately $151.5^{\circ}$.
\end{abstract}

\section{Introduction}

Wettability is an important feature of solid surfaces that is determined by the chemical composition and microstructure of the surfaces ${ }^{[1]}$. In general, two methods can be used to prepare a superhydrophobic surface. The first method is to create roughness on a hydrophobic material surface. The second method is to modify a low-surface-energy material on a rough surface ${ }^{[2-4]}$.

Some plants show superhydrophobic capabilities. Some biomimetic surfaces with superhydrophobicity have been fabricated in the recent years on the basis of a combination of plant surface micro- and nanostructures and chemical compositions by using some synthetic methods ${ }^{[5-8]}$. Wooden structural ceramic has a rich, rough, and porous surface structure, and its pore size ranges from several microns to tens of microns, thus providing great possibilities for its use to prepare superhydrophobic materials. Therefore, the use of natural biological structures as templates to prepare superhydrophobic materials is a new concept.

Zinc oxide $(\mathrm{ZnO})$ is an important semiconductor material, which has found numerous applications such as gas sensors, transparent electrodes, $\mathrm{pH}$ sensors, biosensors, acoustic wave devices, UV photodetectors, and photocatalysts ${ }^{[9-12]}$. Moreover, $\mathrm{ZnO}$ is a very interesting candidate for the preparation of superhydrophobic and self-cleaning films ${ }^{[13]}$. The development of $\mathrm{ZnO}$ surfaces with superhydrophobic properties can expand the range of traditional applications of these devices.

In the present work, we used natural wood lauan as a template to fabricate superhydrophobic biomorphic $\mathrm{ZnO}$ on a carbon substrate $(\mathrm{ZnO} / \mathrm{C})$ mainly through sintering the wood template and chemical modification. Then, the microstructure, crystal structure, bonding mode, and hydrophobicity of the obtained surface were investigated.

\section{Experimental}

\section{Preparation of ZnO/C Superhydrophobic Surface}

Natural-wood lauan was used as the biological plant template. The dried wood was cut into small pieces and sintered in a dry distillation furnace at a heating rate of $2^{\circ} \mathrm{C} / \mathrm{min}$ to $600^{\circ} \mathrm{C}$, after which the samples were kept warm for $2 \mathrm{~h}$. During the sintering, the wood samples were pyrolyzed into 
biomorphic carbon [7]. The biomorphic carbon was then immersed in a $\mathrm{Zn}\left(\mathrm{NO}_{3}\right)_{2}$ solution (3wt\% aqueous solution) for $60 \mathrm{~min}$ under vacuum. After drying, the samples were sintered in a tube furnace in which the air was heated to $200^{\circ} \mathrm{C}$ at a rate of $2^{\circ} \mathrm{C} / \mathrm{min}$. The temperature was then increased to $650^{\circ} \mathrm{C}$ at a rate of $3^{\circ} \mathrm{C} / \mathrm{min}$. A $\mathrm{ZnO}$ coating was thus generated on the carbon substrates. Finally, a $\mathrm{ZnO} / \mathrm{C}$ sample was modified by a fluorine silane solution with isopropanol (at a volume ratio of 1:5) for 5 days and then dried naturally in air.

\section{Characterization}

X-ray diffractometry (XRD, D8 Advance, and Germany) was used to identify the phases of the materials obtained in this study. The surface morphology of the $\mathrm{ZnO} / \mathrm{C}$ samples was examined with field emission scanning electron microscopy (FESEM, Quant 250FEG). A contact angle (CA) measurement instrument (JC2000D2, Shanghai Zhongchen Digital Technology Apparatus Co., Ltd) was used to measure the contact angle of distilled water with a droplet volume of $4 \mu \mathrm{L}$.

\section{Results and Discussion}

\section{Phase Analysis}

Fig. 1 shows the XRD pattern of the as-prepared $\mathrm{ZnO} / \mathrm{C}$ surface obtained by immersing carbon derived from lauan into a $\mathrm{Zn}\left(\mathrm{NO}_{3}\right)_{2}$ solution and sintering it at $650^{\circ} \mathrm{C}$. In addition to the characteristic diffraction peaks of $\mathrm{ZnO}$, there are two steamed bread peaks at $24^{\circ}$ and $43^{\circ}$, which are the amorphous peaks of carbon. This nongraphitizable carbon was obtained from the pyrolysis of the wood during sintering. $\mathrm{ZnO}$ peaks appear along with carbon peaks because $\mathrm{Zn}\left(\mathrm{NO}_{3}\right)_{2}$ on the carbon surface decomposed to $\mathrm{ZnO}$ at high temperature. However, nitrogen peaks were not detected, which indicates that $\mathrm{Zn}\left(\mathrm{NO}_{3}\right)_{2}$ was completely decomposed. Thus, the obtained products were mixed materials, i.e., $\mathrm{ZnO} / \mathrm{C}$.

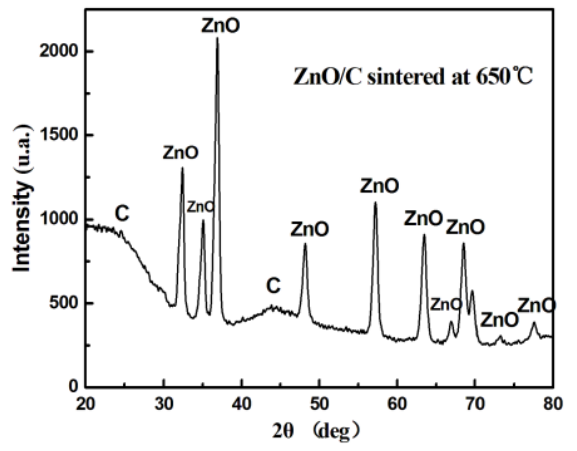

Fig.1 XRD Pattern of ZnO/C Derived from the Lauan

\section{Surface Morphology and Composition Analysis}

Fig.2 shows the surface morphology of the biomorphic carbon and the $\mathrm{ZnO} / \mathrm{C}$ composite materials before and after surface modification with FAS. The surface microstructure of the biomorphic carbon is honeycomb-like, with a nearly hexagonal pore structure with pore sizes ranging from several microns to tens of microns (Fig.2a). In other words, the biomorphic carbon retained the original structure of the wood perfectly. According to the Cassie model, this rough structure facilitates preparation of a superhydrophobic surface. As compared to the original biomorphic carbon, the unmodified $\mathrm{ZnO} / \mathrm{C}$ obtained by immersing the carbon derived from lauan in a $\mathrm{Zn}\left(\mathrm{NO}_{3}\right)_{2}$ solution and sintering it at $650^{\circ} \mathrm{C}$ showed a very similar morphology, as can be seen from Fig.2b. A white $\mathrm{ZnO}$ thin film was formed on both the surface and the internal apertures of the pores. The EDS spectra (Fig.2d) shows a $\mathrm{Zn}$ peak but not a $\mathrm{N}$ peak. This indicates that $\mathrm{Zn}\left(\mathrm{NO}_{3}\right)_{2}$ on 
the surface of carbon decomposed into $\mathrm{ZnO}$, which agrees with the XRD analysis.

Fig. 2c shows the surface morphology of the modified $\mathrm{ZnO} / \mathrm{C}$. From its microstructure, we can see that the surface of the modified $\mathrm{ZnO} / \mathrm{C}$ also retained the original structure of lauan. It can be confirmed that the FAS treatment almost has not been damaged effectively on the products microstructure. The EDS spectrum (Fig.2d) for the modified $\mathrm{ZnO} / \mathrm{C}$ surface shows a peak for F, which demonstrates that FAS covered the surface of the modified $\mathrm{ZnO} / \mathrm{C}$ composite.

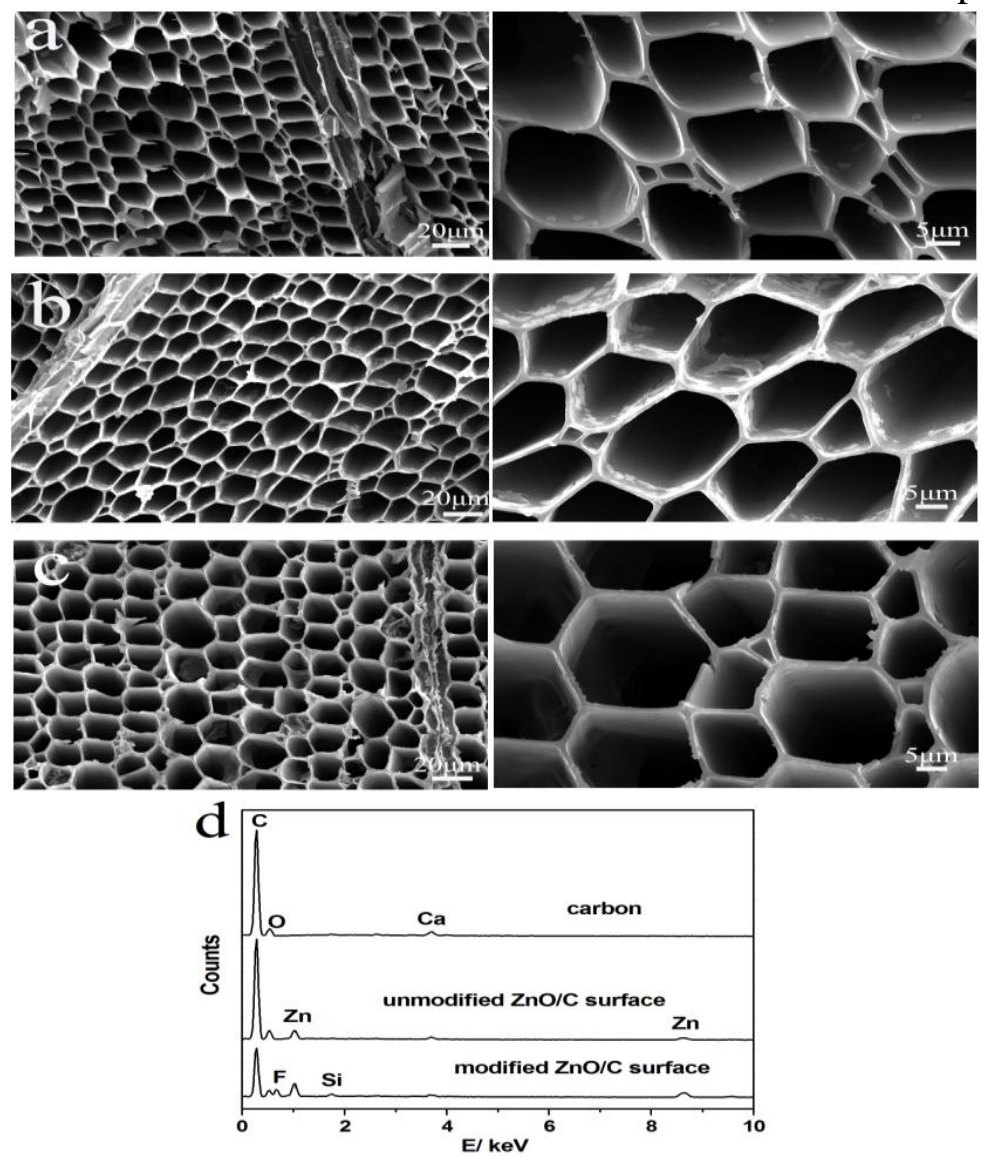

Fig.2 SEM Images of the Surfaces of (a) The Biomorphic Carbon Derived from Lauan, (b) The Unmodified Biomorphic $\mathrm{ZnO} / \mathrm{C}$, and (c) The Modified Biomorphic $\mathrm{ZnO} / \mathrm{C}$, and (d) EDS Spectra of the Surfaces of the Materials in These Figures

\section{Superhydrophobic Properties}

Fig. 3 shows photographs of water drops on the various surfaces. The water droplet CA on the unmodified biomorphic carbon surface derived from lauan wood is $120^{\circ}$, as shown in Fig.3a, indicating some hydrophobic properties. In this case, the porous structure of the carbon reduces the contact area between the droplet and the substrate. The unmodified $\mathrm{ZnO} / \mathrm{C}$ surface was hydrophilic, showing a water droplet CA of approximately $77^{\circ}$ (Fig.3b). These results indicate that the chemical composition also plays an important role in the hydrophobicity. However, the modified $\mathrm{ZnO} / \mathrm{C}$ surface showed significant wettability. After having been modified with the former low-energy FAS coating, the initial hydrophobic sample reached a very high water CA of approximately $151.5^{\circ}$ (Fig.3c). As expected, the modification of a low-surface-energy material can affect its wettability. The water CA of the modified smooth carbon was only $114^{\circ}$, as shown in Fig. $3 \mathrm{~d}$. Thus, surface roughness also plays an important role in the generation of superhydrophobicity. The water droplet was almost spherical on the modified $\mathrm{ZnO} / \mathrm{C}$, as seen in Fig.3e. 

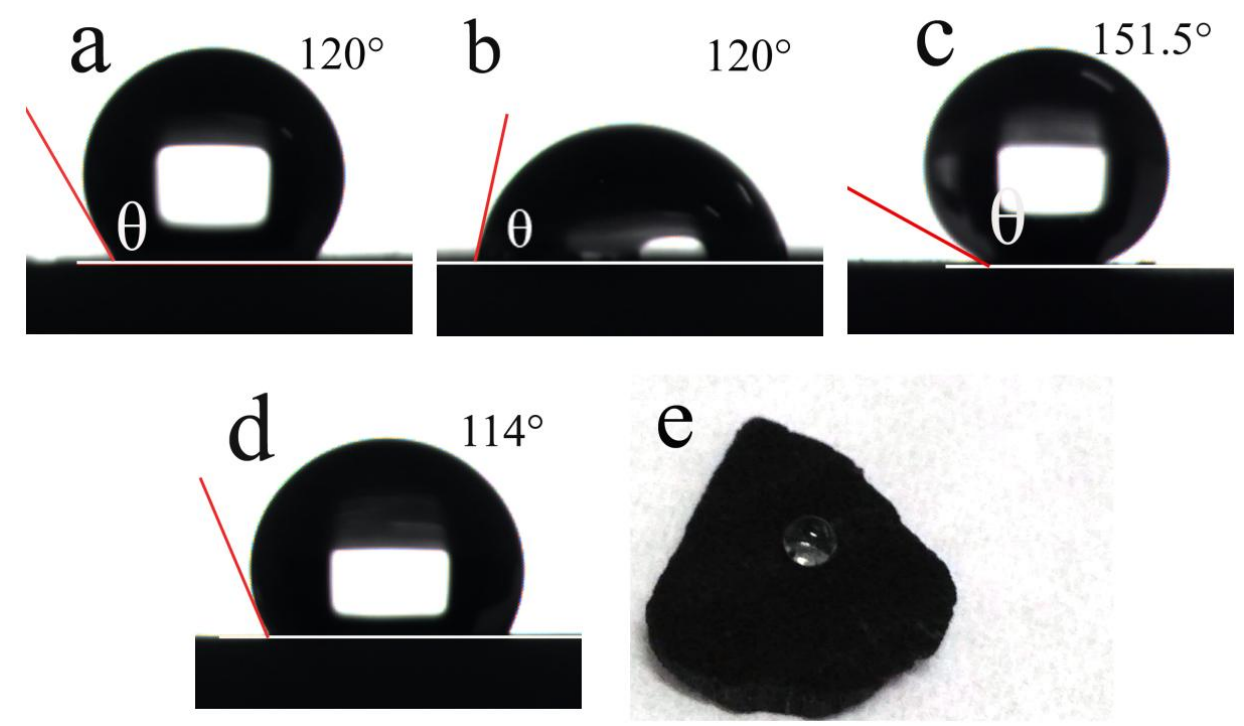

Fig.3 Images of Water CA of the (a) Biomorphic Carbon Derived from Lauan (120 $)$, (b) Unmodified $\mathrm{ZnO} / \mathrm{C}\left(77^{\circ}\right)$, (c) Modified $\mathrm{ZnO} / \mathrm{C}\left(151.5^{\circ}\right)$, (d) Modified Smooth Carbon $\left(114^{\circ}\right)$, and (e) Macro-photograph of Droplet on the Modified $\mathrm{ZnO} / \mathrm{C}$

\section{Conclusions}

A stable superhydrophobic $\mathrm{ZnO} / \mathrm{C}$ surface was obtained by a chemical solution method, sintering, and effective modification. The biomorphic carbon surface showed a honeycomb-like porous structure, which directly increased the surface roughness. The unmodified $\mathrm{ZnO} / \mathrm{C}$ surface can be tailored into a superhydrophobic surface by further fluoride treatment, which decreases the surface free energy significantly. The modified $\mathrm{ZnO} / \mathrm{C}$ surface exhibited excellent superhydrophobic properties, with a water CA of $151.5^{\circ}$. As compared to artificial imitation or other preparation method, this approach can be used to prepare superhydrophobic ceramics with high fidelity to the surface structure of the original wood. The use of a lauan template in the present study may provide a new way to fabricate superhydrophobic surfaces.

\section{Acknowledgements}

The authors wish to express thanks to the Fundamental Research Funds for the Central Universities (30916012203).

\section{References}

[1] Y.T. Cheng, D.E. Rodak, A. Angelopoulos, Microscopic observations of condensation of water on lotus leaves, Appl. Phys. Lett. 87 (2005) 194112-194113.

[2] G. Kwak, M. Seol, Y. Tak, K. Yong, Superhydrophobic ZnO Nanowire Surface: Chemical Modification and Effects of UV Irradiation, J. Phys. Chem. C 113 (2009) 12085-12089.

[3] Th. Pauporté, G. Bataille, L. Joulaud, F.J. Vermersch, Well-Aligned ZnO Nanowire Arrays Prepared by Seed-Layer-Free Electrodeposition and Their Cassie-Wenzel Transition after Hydrophobization, J. Phys. Chem. C 114 (2010) 194-202.

[4] J.Y. Lao, J.Y. Huang, D.Z. Wang, Z.F. Ren, ZnO Nanobridges and Nanonails, Nano. Lett. 3 (2003) 235-238.

[5] W. Barthlott, C. Neinhuis, Purity of the sacred lotus, or escape from contamination in biological surfaces, Planta 202.1(1997):1-8. 
[6] T. Wang, L. Chang, S. Yang, Hydrophobic properties of biomorphic carbon surfaces prepared by sintering lotus leaves, Ceram. Inter. 39 (2013) 8165-8172.

[7] T. Wang, T. Fan, D. Zhang, G. Zhang, Fabrication and the wear behaviors of the carbon/aluminum composites based on wood templates, Carbon 44 (2006) 900-906.

[8] L. Chang, T. Wang, J. Kong, Biomimetic Fabrication of Indicalamus-Leaf-Like Structured Copper Surface with Superhydrophobic Properties, Mater. Trans. 54 (2013) 2297-2300.

[9] B.B. Rao, Zinc oxide ceramic semi-conductor gas sensor for ethanol vapour, Mater. Chem. Phys. 64 (2000) 62-65.

[10] M.H. Asif, O. Nur, M. Willander, Joint frequency offset estimation and multiuser detection using genetic algorithm in MC-CDMA, Biosensors and Bioelectronics 24 (2009) 3379-3382.

[11] C. Xia, N. Wang, L. Lidong, Synthesis and characterization of waxberry-like microstructures ZnO for biosensors, Sensors and Actuators B: Chemical 129 (2008) 268-273.

[12] C.Y. Liu, B.P. Zhang, Z.W. Lu, Fabrication and characterization of ZnO film based UV photodetector, Journal of Materials Science: Materials in Electronics 20 (2009) 197-201.

[13] J. Wu, J. Xia, W. Lei, B.P. Wang, A one-step method to fabricate lotus leaves-like ZnO film, Mater. Lett. 65 (2011) 477-479. 